\title{
La Psicología Ambiental-Comunitaria en el Estudio de los Desastres: La Importancia de los Vínculos Socioespaciales
}

\section{Environmental-Community Psychology in the Study of Disasters: The Importance of Socio-Spatial Links}

\author{
Héctor Berroeta y Laís Pinto de Carvalho \\ Universidad de Valparaíso
}

\begin{abstract}
La literatura psicosocial en contextos de desastres socionaturales se ha enfocado mayoritariamente en el estudio de las consecuencias psicológicas en las personas afectadas, dejando en un segundo plano los factores psicosocioambientales. Nos proponemos aquí destacar la pertinencia de una psicología ambiental comunitaria, para analizar tanto aspectos subjetivos de la relación con el lugar como las relaciones comunitarias de las localidades afectadas por desastres. Para ello, presentamos un marco conceptual de categorías de la psicología comunitaria y la psicología ambiental, pertinentes para estudiar lo que denominamos vínculos socioespaciales en situaciones de desastre socionatural. Se ilustra esta perspectiva presentando resultados de una investigación realizada con metodología mixta, que describe cómo emergen estos vínculos en personas que han vivido en comunidades afectadas por terremotos, tsunami y erupción volcánica en 4 localidades en Chile. Se analizaron las respuestas a las escalas de apego al lugar, identidad de lugar, satisfacción residencial, sentido de comunidad y participación cívica en una muestra no probabilística por conveniencia $(n=628)$, y relatos de 17 grupos focales $(n=117)$ sobre los significados construidos del espacio público. Se concluye que la articulación de la psicología ambiental y comunitaria amplía el entendimiento de elementos de poder y disputa del territorio, así como visibiliza falencias psicosociales en las soluciones de reconstrucción post-desastres.
\end{abstract}

Palabras clave: desastre socionatural, psicología ambiental comunitaria, apego al lugar, satisfacción residencial, espacio público comunitario

\begin{abstract}
The psychosocial literature in contexts of socio-natural disasters has mainly focused on the study of the psychological consequences for the people affected, paying less attention to psycho-socioenvironmental factors. In this article, we aim to highlight the relevance of community environmental psychology for analyzing both the subjective aspects of people-place relationships and the community relations of the towns hit by disasters. To do this, we present a conceptual framework community psychology and environmental psychology categories which are relevant for studying what we call socio-spatial links in socio-natural disaster situations. This perspective is illustrated by presenting the results of a study carried out with a mixed methodology, which describes how these links emerge in people who have lived in communities affected by earthquakes, a tsunami, and a volcanic eruption in 4 Chilean towns. Responses to the scales of place attachment, place identity, residential satisfaction, sense of community, and civic participation were analyzed in a non-probability (convenience) sample ( $\mathrm{n}=628)$, along with reports of 17 focus groups $(n=117)$ on the constructed meanings of public space. It is concluded that the articulation of environmental and community psychology broadens our understanding of elements of power and dispute in the territory, while also making psychosocial flaws visible in post-disaster reconstruction solutions.
\end{abstract}

Keywords: socio-natural disaster, environmental-community psychology, place attachment, residential satisfaction, community public space

Las consecuencias negativas que produce un evento "natural" es lo que se denomina comúnmente desastre "natural". Esta manera de nombrar el fenómeno naturaliza un relato determinista, minimizando el papel de las personas en las causas, consecuencias y restauración de un desastre. Buscando desnaturalizar el fenómeno, las ciencias sociales han insistido en que los desastres no son naturales (Maskrey, 1993). Por lo anterior, en este artículo utilizaremos la noción de desastre socionatural como una intencionalidad discursiva, ya que las amenazas naturales deben interactuar con condiciones de vulnerabilidad social para

Héctor Berroeta y Laís Pinto de Carvalho, Escuela de Psicología, Facultad de Ciencias Sociales, Universidad de Valparaíso, Chile.

Este artículo ha sido financiado por el proyecto FONDECYT N¹1121596, del año 2013, "Vínculos socioespaciales en contextos de transformación urbana producida por catástrofes naturales", y por el proyecto FONDECYT N¹181429, del año 2018, "Vínculos socioespaciales y Desastres socionaturales: un análisis de las prácticas de ensamblaje en los procesos de re-vinculación con el entorno transformado en comunidades afectadas en Chile”, ambos otorgados por la Comisión Nacional de Investigación Científica y Tecnológica de Chile a Héctor Berroeta como investigador principal.

El artículo es parte del trabajo que los autores realizan en el Centro de Investigaciones de Vulnerabilidades e Informalidades Territoriales de la Universidad de Valparaíso. La correspondencia relativa a este artículo debe ser dirigida a Héctor Berroeta, Universidad de Valparaíso, Hontaneda 2653, Valparaíso, Chile. E-mail: hector.berroeta@uv.cl. 
que se configure un desastre. En ese sentido, las decisiones de asentamiento y las condiciones sociales, políticas, culturales y económicas son factores decisivos (Maskrey, 1993; Wisner, Blaikie, Cannon \& Davis, 2003). De esta manera, la participación de otras disciplinas es fundamental, en conjunto con las ciencias naturales y físicas, en la comprensión e intervención de los desastres socionaturales.

Esta relación de inseparabilidad entre naturaleza y sociedad es consistente con la perspectiva transaccional de la psicología ambiental (Altman \& Rogoff, 1987), la que plantea que persona y entorno se definen dinámicamente y se transforman mutuamente a lo largo del tiempo. Desde esta perspectiva, es coherente comprender, entonces, que amenazas naturales, tales como terremotos, tsunamis y volcanes, solamente se materializan en un desastre cuando interactúan con grupos humanos expuestos, asumiendo que la afectación ante un evento es diferenciada por distintos aspectos, tales como estatus socioeconómico, género, etnia, edad, discapacidad, estatus de inmigración, cultura, relaciones de poder y sistemas políticoeconómicos (Wisner et al., 2003).

En este contexto, analizar aspectos subjetivos de la disrupción del vínculo persona-entorno en la configuración del desastre es importante. La literatura psicosocial sobre desastres se ha centrado mayoritariamente en el estudio de las consecuencias psicológicas en las personas afectadas (Bonanno, Galea, Bucciarelli \& Vlahow, 2006; García Martínez, Reyes Reyes \& Cova Solar, 2014). Sabemos sobre los efectos psicológicos en relación a la magnitud de la destrucción, las características demográficas y sociales de quienes habitan estos territorios (Norris, Friedman \& Watson, 2002), el papel que juega la capacidad de organización, comunicación y apoyo social (Páez Basabe, Bosco, Campos \& Ubillos, 2011), la relación entre severidad de la reacción psicológica y el bienestar (García et al., 2014) y el impacto de la pérdida material y su relación con el arraigo (Sanders, Bowie \& Bowie, 2004). Sin embargo, aun cuando entendemos que los cambios residenciales o las transformaciones del hábitat urbano impactan directamente en los vínculos que las personas conforman con los lugares, produciendo quiebres y disrupciones (Boğaç, 2009; Brown \& Perkins, 1992; Fried, 1963; Manzo, 2014), sabemos poco sobre los factores psicoambientales involucrados en las transformaciones producidas por desastres y los procesos de reconstrucción. Analizar estos vínculos es fundamental para posibilitar la planificación de acciones de prevención y reconstrucción que reconozcan las tensiones y dinámicas de contestación del territorio, de modo de respetar derechos, significados y modos de vida de las comunidades (Berroeta et al., 2017; Pinto de Carvalho \& Cornejo, 2018; Scannell, Cox \& Fletcher, 2017; Scannell, Cox, Fletcher \& Heykoop, 2016). En este sentido, desde la psicología, son dos las subdisciplinas que mayormente pueden aportar en esta dirección, la psicología ambiental y la psicología comunitaria. Recientemente hemos explorado la articulación de estos dos campos en los estudios de desastres ocurridos en Chile, hemos observado que las transformaciones producidas a partir de los desastres y los subsecuentes procesos de reconstrucción y/o desplazamiento alteran los entornos físicos de las personas, modificando la construcción del simbolismo y la significación espacial, afectando las dinámicas de convivencia y asociación de las comunidades (Berroeta, Carvalho \& Di Masso, 2016; Berroeta, Ramoneda \& Opazo, 2015).

En este texto nos proponemos destacar la pertinencia de una psicología ambiental comunitaria, para analizar tanto aspectos subjetivos de la relación con el lugar como las relaciones comunitarias de las localidades afectadas por desastres. Para ello, expondremos un breve marco conceptual que presenta el uso de categorías de la psicología comunitaria y la psicología ambiental, para estudiar lo que denominamos vínculos socioespaciales en situaciones de desastre socionatural, presentando resultados integrados del proyecto de investigación FONDECYT N 11121596, del año 2013, y del proyecto FONDECYT $\mathrm{N}^{\circ} 1181429$, del año 2018, que, desde una metodología mixta, describe como se presentan estos vínculos en personas que han vivido desastres en Chile. Caracterizamos los conceptos de apego al lugar, identidad de lugar, satisfacción residencial, sentido de comunidad, participación cívica y significados construidos sobre el espacio público.

\section{Psicología Ambiental Comunitaria, Vínculos Socioespaciales en Contextos de Transformación del Entorno}

La psicología ambiental comunitaria es la denominación que se ha utilizado para referirse a un campo de análisis e intervención, que, como señala Montero (2004), transita entre la psicología ambiental y comunitaria, y que se caracteriza por explorar la interrelación entre las dimensiones sociofísicas y las dinámicas comunitarias. Desde sus orígenes, la psicología comunitaria ha puesto en el centro de sus preocupaciones el análisis de los fenómenos psicosociales que producen transformaciones ambientales que favorecen el desarrollo de las comunidades (Montero, 2004) y, por su parte, la psicología ambiental se ha interesado en estudiar cómo los ambientes físicos se relacionan con los procesos psicológicos asociados a la 
experiencia humana con el lugar. Esta vinculación entre ambos campos disciplinares es abordada por dos principales vías de aproximación: una primera, que plantea una reflexión integradora desde el punto de encuentro en la comunidad y, una segunda, que busca analizar los supuestos epistemológicos de los constructos espacio, entorno y espacio comunitario en estos dos campos, explorando la superación de la dicotomía sujeto-espacio (Berroeta, 2007).

En este sentido, consideramos que el vínculo ambiental-comunitario implica una diferenciación de las tradicionales aproximaciones de la psicología ambiental — de predominio sociocognitivo—, asumiendo una concepción transaccional-subjetivista (Guba \& Lincoln, 1994), distinción que dialoga con los planteamientos fundantes de Wiesenfeld (2001), quien considera el vínculo entre la psicología ambiental y la psicología comunitaria desde el siguiente principio:

no vislumbramos la existencia de seres humanos sin el referente espacial y viceversa, éstos sin personas (...) no concebimos al ambiente como una realidad objetiva, independiente de nuestro modo de acceso a ella, sino que la realidad intersubjetiva que las personas construyen en su interacción social (...) diferentes contextos y experiencias generan diversas significaciones sobre el ambiente y las mismas son históricas y dinámicas. (p. 7)

Si bien la literatura que aborda conceptualmente la articulación de estos dos campos es escasa (Berroeta, 2007; Manzo \& Perkins, 2006; Wiesenfeld, 2001), las experiencias aplicadas son numerosas. En general, se han explicado los procesos de conexión con el lugar y las comunidades desde diversas propuestas conceptuales, las que giran, de una u otra forma, en torno a la pertenencia y a la participación, activa o pasiva, de las personas con sus entornos (McMillan \& Chavis, 1986; Proshansky, Fabian \& Kaminoff, 1983; Scannell \& Gifford, 2010; Silver \& Grek-Martin, 2015; Vick \& Perkins, 2013; Vidal Moranta \& Pol Urrútia, 2005).

$\mathrm{Al}$ respecto, sabemos que el simbolismo espacial se configura por el significado asociado a las características físicas de una estructura espacial, al uso o a las interacciones simbólicas que se producen entre quienes lo utilizan (Valera, 1996) y, por otra parte, que la conexión grupal con el lugar es producto de la experiencia que se da a partir de la reunión entre miembros de un grupo en actividades colectivas en espacios determinados (Berroeta \& Rodriguez, 2012). En consecuencia, la incorporación de estrategias de intervención que favorecen la identificación grupal o comunitaria de los habitantes con los espacios que habitan permite un anclaje social que propicia un uso sostenible, expresado en el cuidado por la estructura física, la calidad y el valor del espacio (Berroeta \& Rodriguez, 2010).

En continuidad con estos hallazgos, desde una perspectiva psicoambiental comunitaria, proponemos analizar la disrupción de los vínculos que se produce tras un desastre, desde un marco que aborde tanto aspectos espaciales como subjetivos (Manzo \& Perkins, 2006; Vidal, Berroeta, Di Masso, Valera \& Peró, 2013), explorando los vínculos con el lugar y entre las personas que lo habitan.

Los vínculos con el lugar se despliegan de un modo complejo y multifacético, lo que requiere una reflexión sobre las condiciones en que viven las personas que son afectadas por un desastre. Las diferencias de calidad entre los viejos y los nuevos entornos residenciales y las oportunidades para relacionarse, satisfacer necesidades de autoestima, sistemas de control y cambio comunitario (Heller, 1982; Manzo, 2014) son aspectos centrales del proceso de evaluación que realizan las personas afectadas; es así que, por ejemplo, el desplazamiento forzado por un desastre es una experiencia emocional negativa que puede contribuir al fortalecimiento de la evaluación del vínculo con el lugar que se abandona (Berroeta et al., 2015), del mismo modo que las políticas de reconstrucción centradas en la sola satisfacción de las personas con su vivienda no aseguran una mayor calidad de vida (Berroeta et al., 2015). Por otra parte, desde una perspectiva construccionista-discursiva, Di Masso, Dixon y Hernández (2016) proponen que la evaluación ambiental es también un proceso político, de carácter ideológico, en donde las prácticas de participación de las personas desplazadas en la toma de decisiones con respecto a su relocalización resultan fundamentales para el proceso de apropiación y vinculación al nuevo entorno (Berroeta et al., 2016).

En suma, proponemos el término vínculo socioespacial como una categoría para la psicología ambiental comunitaria, que permite explorar la relación con los entornos socio-físicos que desarrollan las personas y que agrupa distintos conceptos que la literatura, tanto de la psicología ambiental como comunitaria, han utilizado para estudiar la escala de barrio: sentido de comunidad (McMillan \& Chavis, 1986), satisfacción residencial (Aragonés, Amérigo \& Pérez-López, 2017; Vick \& Perkins, 2013), participación cívica (Long \& Perkins, 2003), identidad de lugar (Proshansky et al., 1983), apego al lugar (Altman \& Low, 1992) y espacio público comunitario (Berroeta \& Vidal, 2012). 
BERROETA Y PINTO DE CARVALHO

\section{Sentido de Comunidad, Satisfacción Residencial y Participación Cívica}

El sentido de comunidad se refiere a los vínculos sociales entre las personas y los lugares y sus implicancias físicas, simbólicas, políticas y culturales en la comunidad (Mannarini, Tartaglia, Fedi \& Greganti, 2006). Es una experiencia de evaluación individual o colectiva que opera como un recurso de la vida en comunidad (Nowel \& Boyd, 2010). Se ha asociado al capital social (Norris, Stevens, Pfefferbaum, Wyche \& Pfefferbaum, 2008), al bienestar psicológico y al compromiso comunitario (Nowel \& Boyd, 2010). El sentido de comunidad influye en el ajuste psicológico de la experiencia de transformación del entorno (Greenfield \& Marks, 2010), desempeñando un papel importante en la revitalización de los vecindarios (Manzo \& Perkins, 2006). Donde no hay conexión emocional de las personas a los lugares, estas no suelen estar lo suficientemente comprometidas para trabajar con vecinos e instituciones locales en el mejoramiento de su entorno.

Con semejanza a lo anterior, la satisfacción residencial también conlleva una experiencia de evaluación, que, según Aragonés et al. (2017), involucra tres grandes componentes: la casa, el barrio y los vecinos. No es un proceso estable ni permanente, siendo afectado por transformaciones del entorno y de la persona. Implica procesos de ajuste y adaptación entre los niveles de aspiración y las necesidades no satisfechas por el ambiente residencial (Sararit, 2018).

La participación cívica, por su parte, incluye la participación en las actividades del barrio y se operacionaliza a través de la pertenencia a entidades o asistencia a actividades (Long \& Perkins, 2003). La participación en los asuntos del barrio ha sido relacionada con el apego al barrio (Cuba \& Hummon, 1993) y su apropiación (Vidal Moranta \& Pol Urrútia, 2005), pudiendo también reflejar el sentido de comunidad y la satisfacción residencial de los habitantes (Francis, Giles-Corti, Wood \& Knuiman, 2012).

\section{Identidad y Apego al Lugar}

El planteamiento central sobre la identidad de lugar es que la identidad personal del individuo se construye en relación con su entorno físico, al igual que su identidad social se construye en relación con su pertenencia a otras categorías sociales, como el sexo, la raza o la clase social (Proshansky et al., 1983; Vidal Moranta \& Pol Urrútia, 2005). Por su parte, Bernardo y Palma-Oliveira (2016) indican que la identidad de lugar se refiere no solamente a una experiencia individual, sino también comunitaria, siendo las conexiones establecidas entre personas y el ambiente físico en el que se encuentran, así como las dinámicas compartidas de identidad de lugar, el fundamento de la conformación de vínculos comunitarios de pertenencia y vecindad.

Esta noción de pertenencia, que se desprende del concepto de identidad, podemos relacionarla con el apego al lugar, considerándolo como los sentimientos afectivos que las personas desarrollan hacia los lugares en donde nacen y viven (Manzo, 2003). Esta definición es difusa y, en los últimos años, en la literatura (Casakin, Hernandez \& Ruiz, 2015; Lewicka, 2011) se ha optado por utilizar el concepto de apego al lugar como un término "paraguas" para referirse al conjunto de los vínculos que las personas establecen con los lugares (Trąbka, 2019). Desde la tradición empírica positivista, el apego al lugar se define como "un vínculo afectivo que las personas establecen con un lugar determinado, donde tienden a permanecer, sentirse cómodos y seguros" (Hidalgo \& Hernández, 2001, p. 274). Este vínculo afectivo se puede desarrollar hacia lugares de diferentes escalas, como la casa, el barrio o la ciudad (Vidal, Valera \& Peró, 2010). Desde una aproximación holística del vínculo persona-ambiente, representada por Altman y Low (1992), se considera el apego al lugar como los afectos, emociones, sentimientos, creencias, pensamientos, conocimientos, acciones y conductas asociados a un lugar, que pueden variar en escala y especificidad; actores (personas, grupos o colectivos culturales); relaciones sociales (interpersonales, de comunidad o culturales, a las que las personas se vinculan a través del lugar); y el tiempo (como pasado, presente y futuro, además de cíclico, con significados y actividades recurrentes). Aproximaciones recientes a la identidad de lugar y al apego de lugar son las perspectivas discursivas que conciben el apego como un recurso culturalmente disponible que se despliega en determinados contextos interaccionales (Di Masso, Dixon \& Durrheim, 2014; Di Masso et al., 2016) y las perspectivas postdiscursivas que consideran las prácticas significantes no lingüísticas en la producción del espacio (Berroeta et al., 2017; Di Masso \& Dixon, 2015).

\section{Espacio Público Comunitario}

El espacio público es una noción que considera que el espacio está conformado por procesos de construcción de ciudadanía y encuentro social, anclado a la reflexión política acerca de lo público-privado, la accesibilidad, transparencia y libertad. El concepto de espacio público es estudiado en sus dimensiones 
urbanas y sociales, integrando teorías del diseño urbano y de las ciencias sociales. Se refiere también a aspectos de la promoción o el control de la sociabilidad y el encuentro social que se produce en la construcción de la ciudad (Borja \& Muxí, 2001; Salcedo Hansen, 2002). Es posible identificar tres grandes perspectivas o tendencias discursivas que se sitúan en la base de las políticas de representación del espacio público, tres visiones distintas sobre el pasado y el futuro de los espacios públicos en relación a los cambios contemporáneos en la vida pública, y sus presuposiciones y argumentos muestran sensibilidades analíticas dispares, con consecuencias políticas e ideológicas notablemente diferentes. Estas tres visiones son la tesis terminal o de espacio público perdido, la tesis optimista o la construcción de civilidad y la tesis conflictivista o del control y disputa (Berroeta \& Vidal, 2012; Berroeta et al., 2016; Di Masso, Berroeta \& Vidal, 2017).

El planteamiento de un espacio público comunitario quiere connotar los fenómenos socioespaciales resultantes de las maneras particulares en que interactúan las características físicas, los usos y los significados asociados al espacio público en la escala de barrio (Berroeta \& Vidal, 2012). Con esto se acentúa la importancia de la interrelación entre individuos y ambiente, la interacción entre personas vecinas, sus redes y su vida cotidiana comunitaria (Berroeta et al., 2015).

De modo de ilustrar la pertinencia y alcances de una lectura desde la psicología ambiental comunitaria para el estudio de comunidades en contexto de transformaciones producidas por desastres socionaturales en Chile, presentaremos brevemente cuatro casos en los cuales hemos desarrollado esta investigación: las transformaciones de las ciudades de Chaitén, Constitución, Dichato y Tocopilla.

\section{Transformaciones Producidas por Desastres Socionaturales}

Chile es un país sometido a diversos y continuos desastres socionaturales (Organización de las Naciones Unidas para la Educación, la Ciencia y la Cultura, 2012) que producen transformaciones urbanas profundas. En esta investigación nos propusimos analizar eventos de gran impacto nacional que han sido emblemáticos en los últimos años y que produjeron distintos cambios en el entorno, dando origen a distintas soluciones para la reconstrucción. Las estrategias utilizadas por el gobierno chileno para abordar la reconstrucción han sido diversas y erráticas (Tapia, 2015). Tal como describe Salgado (2014), el modelo implementado es predominantemente neoliberal, negando a la ciudadanía la co-construcción de los territorios.

Las transformaciones en los hábitats de las comunidades a consecuencia de estos desastres fueron principalmente de dos tipos: totales (cuando implicaron cambios en la ubicación de viviendas dentro o fuera de la ciudad de origen) y transformaciones parciales (cuando se mantuvo el emplazamiento original de la vivienda).

\section{Transformación Total: Chaitén, 2008}

El 2 de mayo de 2008, producto de la erupción del volcán Chaitén, fueron evacuadas 4.700 personas habitantes de la región. Tras la erupción volcánica, la mayoría de las viviendas fueron compradas por el Estado y se entregó un subsidio individual de subsistencia por 18 meses, con el cual cada familia debía buscar una solución en el mercado inmobiliario regular. Esta estrategia dificultó la organización de la comunidad, esparciendo a la población por diversas ciudades de la región de Los Lagos. Una de las localidades que recibió un número considerable de chaiteninos (200 familias aproximadamente) fue la comuna de Puerto Montt, específicamente la localidad de Alerce, donde viven cerca de 60 mil personas (Chile, Ministerio del Interior y Seguridad Pública, 2014).

\section{Transformación Total: Dichato, 2010}

Ante el gran terremoto y tsunami del 27 de febrero de 2010, más del 80\% de Dichato fue devastado. Los daños de la localidad provocaron que toda la población que vivía en la zona costera fuera erradicada temporalmente en aldeas de emergencia en zonas altas de seguridad. En esta situación, la Aldea El Molino, en Dichato, llegó a ser considerada la aldea de emergencia postterremoto más grande de Chile, albergando aproximadamente a 450 familias por más de tres años. El proceso de reconstrucción fue lento, generando la conformación de comités y enfrentamiento con las autoridades. Dos de los conjuntos habitacionales terminados a los tres años del desastre y con los cuales trabajamos en esta investigación fueron Villa Horizonte y Bahía Azul (Chile, Gobierno Regional Bío Bío, 2010). 


\section{Transformación Parcial: Constitución, 2010}

En el año 2010, Constitución también fue muy azotada por el terremoto y tsunami del 27 de febrero. Producto de este sismo, una de las comunidades afectadas fue el conjunto habitacional Santa Aurora, emplazado en lo alto del cerro O'Higgins. El conjunto habitacional fue demolido y reconstruido en el mismo emplazamiento. Sus habitantes, pese a las pérdidas materiales y humanas, en su gran mayoría decidió regresar al barrio. Hoy está conformado por departamentos donde residen 48 familias que vivían en el conjunto original (Chile, Gobierno Regional Bío Bío, 2010).

\section{Transformación Parcial: Tocopilla, 2007}

El terremoto de Tocopilla del 14 de noviembre de 2007 provocó daños estructurales mayores en el 58\% de las construcciones e infraestructura de la ciudad, dejando sin hogar a cerca de 15 mil personas. La solución definitiva no mantuvo la vecindad original o la desarrollada en los barrios transitorios en el periodo de espera. Una de estas soluciones fue el barrio Pacífico Sur, con un total de 324 casas, de las cuales 58 acogen a familias provenientes del sector Huellita, 30 de El Teniente y 236 viviendas fueron asignadas a allegados históricos y allegados postterremoto (Chile, Ministerio del Interior y Seguridad Pública, 2014).

\section{Método}

Esta investigación se sitúa desde una perspectiva transaccional (Altman \& Rogoff, 1987). Se considera que persona y entorno son factores inseparables, que se definen dinámicamente y se transforman mutuamente a lo largo del tiempo. Asimismo, se sitúa desde una comprensión del entorno como un constructo sociofísico (Altman \& Rogoff, 1987), en el cual las propiedades físicas y sociales están en interrelación. Siguiendo a Stokols y Shumaker (1981), desde una perspectiva transaccional, la indagación debería realizarse desde múltiples técnicas, las cuales deberían enfatizar el estudio de análisis holísticos, como aspectos inseparables. Esta perspectiva permite dar cuenta de aspectos cualitativos que aborden los significados espaciales, experiencias, prácticas y acciones (por ejemplo, ¿cómo se siente? ¿cómo se experiencia determinado lugar?), sin renunciar a la dimensión evaluativa del componente afectivo e identitario (¿me siento apegado a este barrio? ¿me siento identificado con este barrio?). Desde este marco, se diseñó una investigación de carácter mixto, de la cual reportamos dos aproximaciones al fenómeno de los vínculos socioespaciales en contextos de transformación por desastres socionaturales que describiremos a continuación: una primera aproximación cuantitativa de mediciones individuales y una segunda cualitativa de producción grupal.

Si bien ambas aproximaciones tuvieron momentos de producción de datos y análisis independientes, las integramos a partir de estrategias del análisis selectivo de la grounded theory (Strauss \& Corbin, 1990), es decir, realizamos procesos de reducción y relación de los datos, construyendo nuevas categorías y buscando organizar la información de modo a responder las preguntas emergentes en todos los casos. Como síntesis de este proceso, y siguiendo a Morrow y Smith (1995), construimos una figura que presenta el contexto, las condiciones causales, el fenómeno, las condiciones intervinientes, las estrategias y las consecuencias.

\section{Aproximación 1: Mediciones Individuales}

Participantes. Desde una aproximación cuantitativa, se diseñó una encuesta que fue aplicada en el año 2013 a una muestra no probabilística por conveniencia de 628 habitantes. El total de participantes estaba compuesto por habitantes afectados por la reconstrucción: 144 habitantes desplazados de la ciudad de Chaitén, 193 habitantes de Tocopilla, 80 habitantes de Constitución y 211 habitantes de Dichato. En cuanto a las características de la muestra, el 66,6 \% de las personas encuestadas son mujeres y la edad promedio de la población es de 41 años (DE=14,95). En relación con la vivienda, el 88,7\% de las personas vive en casa propia, el 4\% arrienda y el 7,3\% vive de allegado. En cada vivienda habitan en promedio 3,7 personas.

Instrumentos. El instrumento fue diseñado en su oportunidad a partir de una adaptación de cinco escalas, con el objetivo de medir las dimensiones de apego al lugar social y espacial, identidad de lugar, sentido de comunidad, satisfacción residencial y participación cívica. Las escalas de apego al lugar social, espacial e identidad de lugar se formularon en un autorreporte, evaluando la experiencia en el barrio de origen y en el barrio actual, con el propósito de acceder a una evaluación de la experiencia antes de la transformación por el desastre y a su evaluación actual. 


\section{Escala de apego al lugar social y espacial (Scannell \& Gifford, 2010).}

Escala adaptada de Scannell y Gifford (2010), que evalúa el apego al lugar social y espacial. Está compuesta de ocho ítems con formato de respuesta tipo Likert $(1=$ Nada a $6=$ Muchísimo $)$, que deben ser respondidos con relación al Barrio de origen y al actual (por ejemplo: los espacios públicos del barrio son importantes para mí). La confiabilidad de la escala adaptada medida mediante el coeficiente Alpha de Cronbach, es, para Apego Social pasado, 0,914; para Apego Espacial pasado 0,884; para Apego Social actual 0,898; y para Apego Espacial actual 0,885. La escala en su versión original reporta un Alfa de Cronbach de 0,78.

\section{Escala global de identidad de lugar (Vidal et al., 2010).}

Escala adaptada de Vidal et al. (2010) y tomada de Hernandez, Hidalgo, Salazar y Hess (2007), que evalúa identidad de lugar. Está compuesta de cinco ítems con formato de respuesta tipo Likert $(1=$ Nada a $6=$ Muchísimo), que deben ser respondidos con relación al Barrio de origen y al actual, y a la ciudad (por ejemplo: este barrio forma parte de mi identidad). La confiabilidad de la escala, medida mediante el coeficiente Alpha de Cronbach es, para Identidad de Lugar pasado 0,920 y para Identidad de Lugar actual 0,892. La escala en su versión original reporta un Alfa de Cronbach de 0,94.

\section{Escala breve de sentido de comunidad (Long \& Perkins, 2007).}

Escala adaptada de Long y Perkins (2007), que evalúa sentido de comunidad. Está compuesta de ocho ítems con formato de respuesta tipo Likert $(1=N a d a$ a $6=$ Muchísimo $)$, que deben ser respondidos en relación al Barrio actual (por ejemplo: muchos de mis vecinos me conocen). La confiabilidad de la escala adaptada, medida mediante el coeficiente Alpha de Cronbach es de 0,838. La escala en su versión original reporta un Alfa de Cronbach de 0,74.

\section{Escala de satisfacción residencial (Amérigo, 1995).}

Escala adaptada de Amérigo (1995), que evalúa la satisfacción residencial. Está compuesta de cuatro ítems con formato de respuesta tipo Likert (de $1=$ Nada a $6=$ Muchísimo), que debían ser respondidos con relación al Barrio, a la Vivienda, a los Vecinos y al Global actual (por ejemplo: cuán satisfecho se siente con su casa). La confiabilidad de la escala adaptada, medida mediante el coeficiente Alpha de Cronbach, es de 0,858. La escala en su versión original no reporta Alfa de Cronbach.

\section{Escala de participación cívica (Perkins, Florin, Rich, Wandersman \& Chavis, 1990).}

Escala adaptada de Perkins et al. (1990), que evalúa participación cívica. Está compuesta de diez ítems con formato de respuesta tipo Likert ( $1=$ Nada a $6=$ Muchísimo $)$, que deben ser respondidos con relación al Barrio actual (por ejemplo: participa de alguna forma en su junta de vecinos). La confiabilidad de la escala adaptada, medida mediante el coeficiente Alpha de Cronbach, es de 0,909. La escala en su versión original reporta un Alfa de Cronbach de 0,78.

Procedimiento. El instrumento se aplicó en Alerce, Dichato, Constitución y Tocopilla. Para resguardar el respeto, la autonomía y la confidencialidad de la participación se utilizaron en la investigación documentos de consentimiento informado aprobados por el comité de ética de la Universidad de Valparaíso. El proceso de consentimiento informado consistió en la lectura y firma de estos documentos por cada participante, antes de iniciar la producción de los datos.

Análisis de datos. Se analizaron las dimensiones de apego al lugar social, espacial e identidad de lugar, aplicando la prueba $t$ de Student para identificar si existían diferencias entre localidades y entre las evaluaciones del barrio pasado y actual. Para las dimensiones sentido de comunidad, satisfacción residencial y participación cívica se calcularon los promedios para cada nivel de respuesta Likert, por localidad.

\section{Aproximación 2: Producciones Grupales}

Complementario a lo anterior, y desde una aproximación cualitativa, se realizaron como técnica de producción de datos, grupos focales en las cuatro localidades. 
Participantes. Según lo descrito en Berroeta et al. (2016), los criterios de selección de los barrios fueron la existencia de algún grado de conocimiento previo entre los habitantes de los nuevos barrios y la antigüedad del barrio. En Tocopilla, se seleccionó el barrio Pacífico Sur, que tiene un sector de vecinos que fue reubicado en su conjunto. En Constitución, se seleccionó el conjunto habitacional Santa Aurora, por ser un barrio que fue completamente demolido y reconstruido, manteniendo sus mismos habitantes. En Dichato, se seleccionaron los barrios Villa Horizonte y Bahía Azul, que fueron habitados por personas que residían en sectores muy cercanos. Finalmente, para el caso de Chaitén, se seleccionó la localidad de Alerce en Puerto Montt, donde vive un grupo aproximado de 150 familias desplazadas de Chaitén.

Participaron 117 habitantes, formados por cuatro grupos con personas desplazadas de Chaitén (grupos realizados en Puerto Montt, Los Alerces), tres grupos en Tocopilla, seis grupos en Dichato (cuatro en Villa Horizonte y dos en Bahía Azul) y cuatro en Constitución. La muestra fue de tipo intencional y los criterios de selección fueron: personas mayores de 18 años de ambos sexos, propietarios de sus viviendas, que hubieran residido por más de cinco años en el barrio de origen de la comunidad y que no hubieran sufrido daños físicos ni pérdida de familiares o amigos como consecuencia de los desastres.

La selección de participantes se realizó a partir de quienes señalaron su voluntad durante la aplicación de cuestionarios en una fase previa de la investigación y de la intermediación de informantes clave de cada comunidad.

Instrumento. Durante el año 2014 se realizaron 17 grupos focales. En estos grupos se indagó por la historia del barrio (¿cómo se llegó a construir el barrio? ¿cómo era antes? ¿cómo eran las viviendas, el entorno, la relación con los vecinos?), el proceso de reconstrucción y la decisión de habitar el barrio actual (¿por qué se fueron o no de la localidad donde vivían? ¿cómo fueron los procesos de participación? ¿cómo son las viviendas, el entorno, la relación con vecinos? ¿cómo cuidan de los espacios?). Los grupos fueron grabados y transcritos.

Procedimiento. Todos los grupos fueron realizados en sedes vecinales y conducidos por el primer autor de este artículo. Los procedimientos éticos de investigación se efectuaron mediante lectura y firma de carta de consentimiento informado.

Análisis de la información. La información fue organizada utilizando el software ATLAS.ti 7. El método de análisis se inspiró en el análisis abierto y en el análisis axial de la grounded theory (Strauss \& Corbin, 1990). El análisis siguió una lógica individual, analizando cada localidad por separado, y luego una lógica transversal desde los ejes temático-analíticos emergentes en todos los casos (Cornejo, Mendoza \& Rojas, 2008). Con el propósito de triangular el análisis, los datos fueron codificados e internalizados por el equipo de investigación, conformado por psicólogos y psicólogas ambientales y comunitarios.

El proceso de categorización global fue orientado teóricamente desde los marcos discursivos identificados para los relatos del espacio público. Conceptualmente, estos discursos engloban distintos repertorios interpretativos que definen los significados asociados al espacio público.

Finalmente, integramos las aproximaciones siguiendo una lógica selectiva de la grounded theory (Strauss \& Corbin, 1990), organizando las principales relaciones identificadas.

\section{Resultados}

\section{Mediciones Individuales: Evaluaciones del Barrio Pasado y Actual}

Apego social. En la medición del apego social entre el barrio pasado y el barrio actual, identificamos diferencias en todos los sectores. La variación entre el apego social en el barrio pasado y en el barrio actual no tiene la misma dirección en los cuatro sectores, siendo Constitución el único sector en que el apego social actual es mayor que el del barrio pasado (ver Tabla 1 y Figura 1).

Apego espacial. Todos los sectores presentan diferencias en el apego espacial entre el barrio pasado y el actual, excepto Dichato. La variación entre el promedio de apego espacial en el barrio pasado y el actual no tiene la misma dirección en todos los sectores, siendo Constitución el único sector que presenta dirección ascendente (ver Tabla 1 y Figura 1).

Identidad de lugar. Al analizar las medias de identidad de lugar entre el barrio pasado y en el barrio actual, identificamos que en los cuatro sectores no hay diferencias (ver Tabla 1 y Figura 1). 
Tabla 1

Diferencias de Apego al Lugar Social y Espacial e Identidad de Lugar entre el Barrio Pasado y Actual

\begin{tabular}{|c|c|c|c|c|c|c|c|}
\hline \multirow{2}{*}{ Apego y sector } & \multicolumn{2}{|c|}{ Barrio pasado } & \multicolumn{2}{|c|}{ Barrio actual } & \multirow{2}{*}{$t$} & \multirow{2}{*}{$g l$} & \multirow{2}{*}{$p$} \\
\hline & Promedio & $D E$ & Promedio & $D E$ & & & \\
\hline \multicolumn{8}{|l|}{ Apego al lugar social } \\
\hline Chaitén & 4,86 & 1,35 & 2,94 & 1,44 & 11,970 & 143 & $<0,001$ \\
\hline Constitución & 3,99 & 1,65 & 4,43 & 1,43 & $-2,756$ & 79 & 0,007 \\
\hline Dichato & 3,96 & 1,36 & 3,17 & 1,22 & 6,563 & 210 & $<0,001$ \\
\hline Tocopilla & 3,79 & 1,61 & 3,15 & 1,52 & 3,745 & 192 & $<0,001$ \\
\hline \multicolumn{8}{|c|}{ Apego al lugar espacial } \\
\hline Chaitén & 4,59 & 1,27 & 2,60 & 1,26 & 12,974 & 143 & $<0,001$ \\
\hline Constitución & 2,48 & 1,56 & 4,97 & 1,18 & $-14,057$ & 79 & $<0,001$ \\
\hline Dichato & 3,45 & 1,40 & 3,36 & 1,30 & 0,318 & 210 & 0,484 \\
\hline Tocopilla & 3,24 & 1,62 & 2,89 & 1,47 & 2,279 & 192 & 0,024 \\
\hline \multicolumn{8}{|l|}{ Identidad de lugar } \\
\hline Chaitén & 4,93 & 1,20 & 2,92 & 1,32 & 12,437 & 143 & 0,008 \\
\hline Constitución & 4,30 & 1,49 & 4,68 & 1,47 & $-2,184$ & 79 & 0,032 \\
\hline Dichato & 4,14 & 1,42 & 3,56 & 1,35 & 4,044 & 210 & $<0,001$ \\
\hline Tocopilla & 3,91 & 1,71 & 3,41 & 1,49 & 2,661 & 192 & 0,008 \\
\hline
\end{tabular}

Fuente: Elaboración propia, 2019.

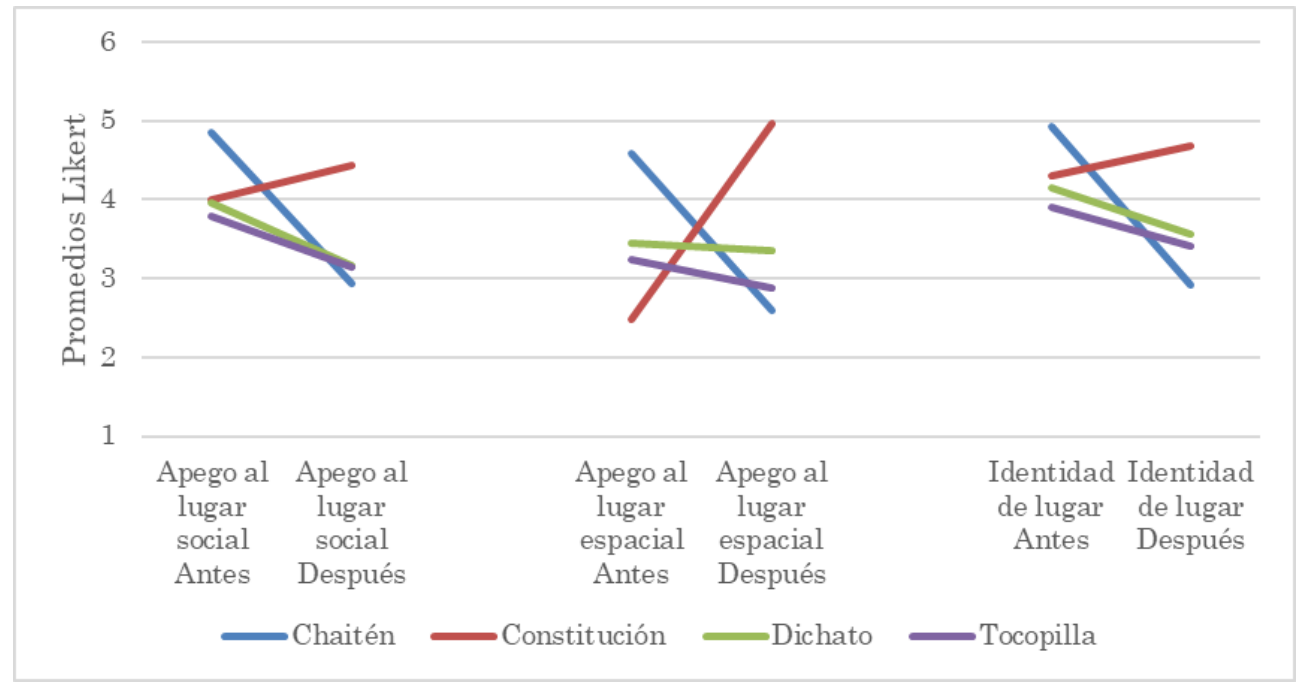

Figura 1. Diferencias de apego al lugar social, espacial e identidad de lugar entre el barrio pasado y actual en cada sector, expresadas en promedios de la escala Likert.

Los cuatro sectores estudiados presentaron en todas las variables diferencias entre las medias obtenidas en referencia al lugar de origen y al lugar actual, con única excepción de Dichato, al no presentar diferencias en el apego espacial. Esto implica que los vínculos socioespaciales son diferentes entre el barrio original y el barrio actual en todos los casos.

De estos resultados, destacan los casos de Chaitén y Constitución. Chaitén, por un lado, presenta los valores más bajos en todas las dimensiones evaluadas en el barrio actual, al contrario de Constitución, que presenta los valores más altos. Esta diferencia de resultados demuestra el impacto que han vividos las personas que se desplazaron de su ciudad hacia Los Alerces, experimentando una transformación total del entorno. Por otro lado, en el conjunto habitacional Santa Aurora en Constitución, la reconstrucción se realizó 
en el mismo lugar en que se ubicaban las viviendas antes del terremoto, manteniendo e incluso aumentando los niveles evaluados.

\section{Sentido de Comunidad y Participación Cívica}

Considerando que 1 corresponde a la respuesta nada y 6 a muchísimo, los resultados obtenidos del sentido de comunidad en el barrio actual nos permiten identificar que los participantes de Constitución presentan un mayor promedio de puntajes en sentido de comunidad, mientras que Dichato, Tocopilla y Chaitén presentan promedios menores. Nuevamente, Chaitén presenta los promedios más bajos respecto del barrio actual (ver Figura 2).

La participación cívica mantiene un patrón similar, sin embargo, con promedios inferiores. Constitución presenta los promedios más altos de participación cívica; sin embargo, representando respuestas entre los puntajes poco (2) y algo (3). Las demás localidades presentan promedios de participación cívica inferiores al nivel poco, siendo Chaitén la localidad con promedios más bajos (ver Figura 2).

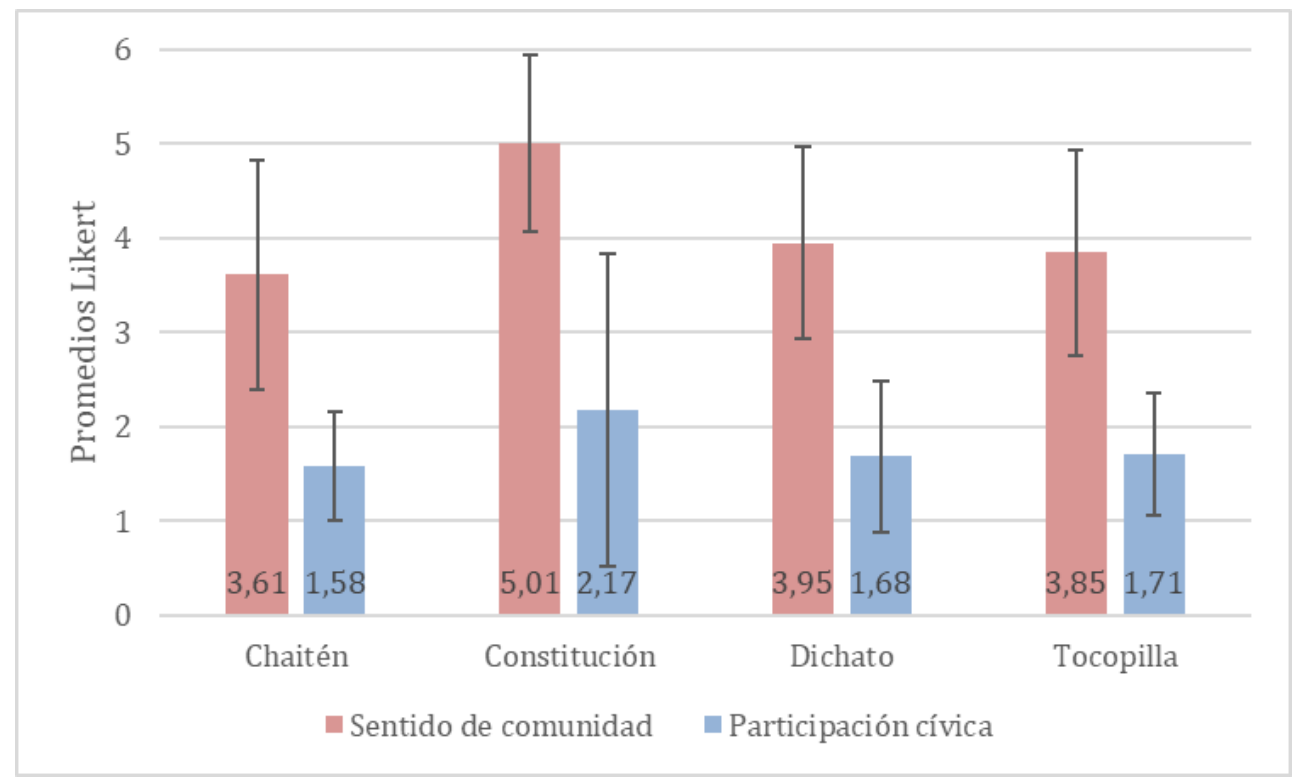

Figura 2. Sentido de comunidad y participación cívica en el barrio actual (en promedios Likert) en cada sector.

\section{Satisfacción Residencial}

A partir de la pregunta ¿cuán satisfecho se siente con su casa?, identificamos que Constitución presenta el promedio más alto de satisfacción con la vivienda actual, con un promedio equivalente al puntaje mucho (5). Tocopilla y Dichato presentan promedios equivalentes entre los puntajes bastante (4) y mucho (5), y Chaitén, presenta el promedio más bajo, con un puntaje equivalente a una respuesta entre algo (3) y bastante (4) (ver Figura 3).

\section{Producciones Grupales: Significados Asociados al Espacio Público}

Las transformaciones por desastres provocan un conjunto de relatos que articulan distintos repertorios discursivos sobre el espacio público. El análisis de estos relatos nos muestra cómo se despliegan los tres grandes marcos discursivos del espacio público — perdido, cívico y en disputa - que condicionan las prácticas de apropiación del lugar (ver Berroeta et al., 2016).

Para el propósito de este artículo, en que presentamos una ilustración de la pertinencia y alcances de una lectura de la psicología ambiental comunitaria para el estudio de comunidades en contexto de transformaciones producidas por desastres socionaturales en Chile, describiremos los tres grandes marcos 
discursivos que identificamos transversalmente en las localidades estudiadas. Para profundizar en estos resultados, revisar Berroeta et al. (2016).

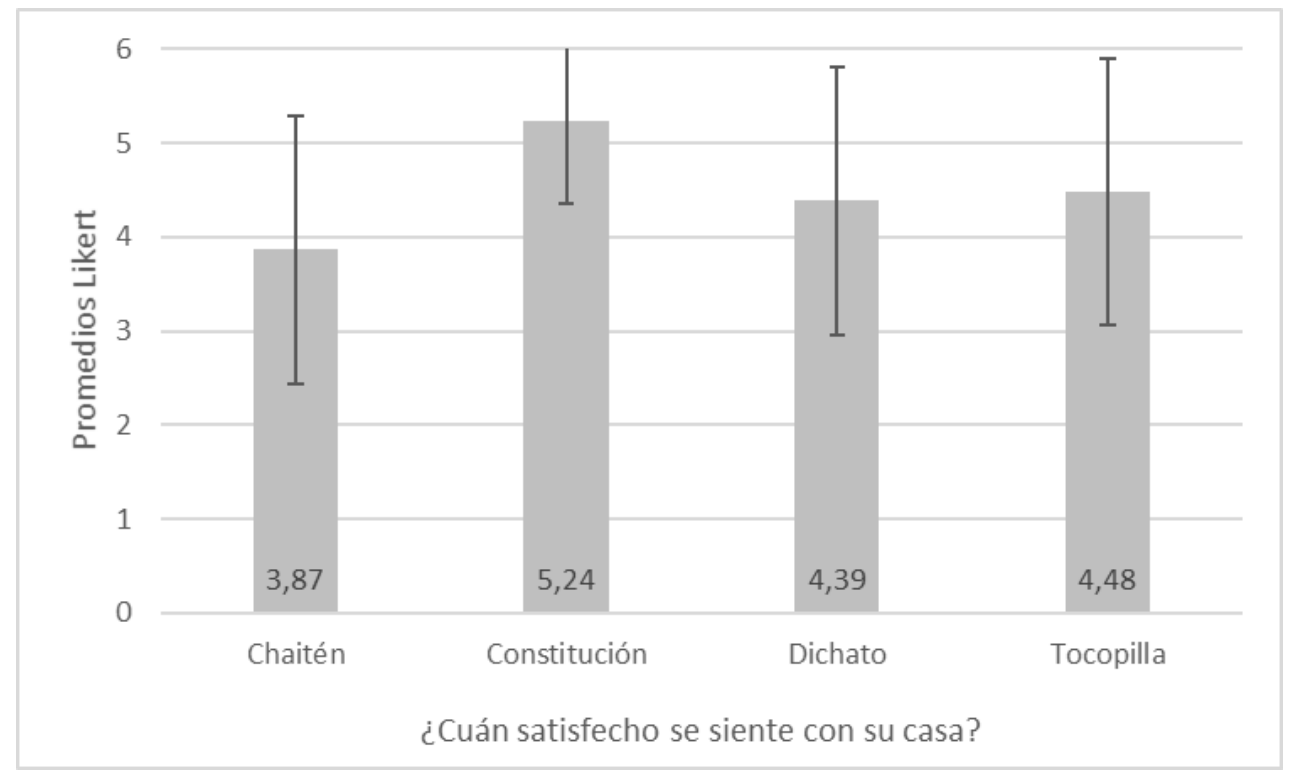

Figura 3. Niveles de satisfacción con la vivienda actual (en promedios Likert) en cada sector.

La pérdida. Identificamos los relatos de la experiencia de las transformaciones por un desastre socionatural que explicitan la pérdida de elementos, tanto individuales como comunitarios, y que convergen en un discurso pesimista. En su conjunto, relatan localidades que ya no son las mismas física y relacionalmente después del evento. Para describir la pérdida, la base del relato de los participantes es la presencia previa de un vínculo con el entorno que se desarrolla en valoraciones hacia el espacio pasado y presente, identificando lo que fue perdido y su consecuente aceptación o malestar. Identificamos las categorías emergentes de arraigo y pérdida de modos de vida, añoranza del espacio perdido y privatización del espacio público.

Estos relatos de pérdida se caracterizan diferentemente según las localidades. Desde la experiencia de habitantes desplazados de Chaitén, la pérdida significa modos de vida que ya no se encuentran, pérdida de la ruralidad con sus lazos y prácticas, valorando estos cambios negativamente y traduciéndolos en descontento. Los discursos de la pérdida también están presentes en Dichato; sin embargo, estos se caracterizan por la resignificación positiva. Las mejorías de las condiciones habitacionales se constituyen en paralelo a la nostalgia de los modos de vida de una ciudad que antes tenía menos visibilidad.

La civilidad. Los relatos que se basan en un discurso cívico y optimista del espacio público transformado por un desastre socionatural conciben de forma importante la adaptación y las prácticas de intervención para mejorar la calidad de vida de los habitantes. Está presente la noción de un espacio perdido, pero en estos relatos el énfasis está en la acción para realizar la ciudadanía. Considerando el proceso de transformación, sus habitantes desarrollan un sentido de resignación del espacio perdido, entendiendo sus prácticas ciudadanas como modos de reapropiación del espacio, especialmente desde la unión comunitaria. Identificamos las categorías emergentes de la "comunidad ideal es la que está unida", "prácticas culturales y vecinales", y "prácticas de cuidado con el espacio público". Estos discursos están presentes en la experiencia de habitantes del conjunto habitacional Santa Aurora en Constitución, especialmente cuando significan la reconstrucción del barrio como una conquista de la unión comunitaria. Emergen también relatos de redes de apoyo económico y emocional en Dichato y Constitución, redes de vecindad a partir de las cuales se transforman y mejoran los espacios. 
El control y la disputa. Las transformaciones producidas por desastres socionaturales revelaron una noción de que el espacio no es controlado libremente por sus habitantes, sino que es un espacio de disputa con el Estado e instituciones privadas. Participantes del estudio demuestran una significación de esta disputa como necesidad de organización comunitaria para contra-controlarla, contestándola con protestas y lucha por la participación en la planificación y toma de decisión sobre las características que adopta el espacio público y las viviendas. Identificamos las categorías emergentes de protestas como herramienta de conquista del espacio y participación para la garantía de derechos en las localidades de Dichato, Constitución y Tocopilla. Estos discursos relevan la participación como un mecanismo fundamental para negociar e incidir en las decisiones del proceso de reconstrucción a través de estrategias de confrontación y colaboración. Otro discurso presente es la significación del espacio como productor de exclusión y estigma, evidenciando experiencias que no estaban presentes antes del desastre, como es el caso de personas desplazadas de Chaitén y habitantes de Bahía Azul (Dichato).

Estos relatos sobre el espacio público son constituidos transversalmente por prácticas y significados. Las prácticas - como la participación comunitaria—y los significados asociados al espacio — como la satisfacción residencial- también son afectados por las transformaciones socioespaciales y son la base para la realización del proceso de apropiación del espacio, en un nivel más abstracto que los elementos anteriores y tridimensionalmente establecidos por ellos. Observamos cómo el sentido ideológico del espacio público se reproduce a partir de las relaciones discursivas que lo justifican.

\section{Integración de Resultados}

Con el fin de ilustrar una lectura de la psicología ambiental comunitaria de los resultados de las aproximaciones que hemos relato, presentamos en la Figura 4 un esquema integrado resultante de la codificación indexada del material producido. En primer lugar, para comprender en contextos de transformación por desastres socionaturales la dinámica de los vínculos socioespaciales que aquí analizamos, es necesario comprender que el riesgo de un desastre solamente se materializa si existen comunidades expuestas a amenazas. A partir de esta premisa, debemos considerar que el modelo político de gestión de los territorios que asumen los gobiernos es también un elemento de base para tomar en consideración una amenaza. Entre los aspectos comunitarios más significativos a considerar, identificamos dos, un marcado énfasis de las acciones gubernamentales en abordar la fase de emergencia, por sobre la programación, prevención y educación postdesastre, y una ausencia de planificación participativa con enfoque comunitario del territorio.

La amenaza de pérdida de la vinculación socioespacial vivida por los habitantes de localidades transformadas por el desastre es, por lo tanto, un proceso psicosocial que configura una acción política. Las estrategias que desplegaron los habitantes frente a esta amenaza fueron identificadas principalmente como la conformación de nuevos discursos sobre el espacio público, la contestación del territorio, la realización de protestas y la mayor participación comunitaria para la garantía de derechos. Estas estrategias emergieron desde los distintos actores de la comunidad, siendo facilitadas por las dinámicas comunitarias de apoyo mutuo en los barrios afectados, mientras que los planes y estrategias de reconstrucción funcionaron principalmente como obstaculizadores, generando la necesidad de lucha por parte de las comunidades con el objetivo de minimizar los efectos no deseados.

Como consecuencia, estas estrategias comunitarias incidieron en el mejoramiento y modificación de algunos de los procesos de reconstrucción, lo que se asocia a la experiencia expresada en los niveles de satisfacción residencial con la vivienda actual, sentido de comunidad y participación cívica, así como en apego e identidad de lugar en aquellas comunidades que desplegaron este tipo de acciones. Al mismo tiempo, estas estrategias comunitarias incidieron en modificaciones y ajustes en los planes y estrategias de reconstrucción, potenciando las dinámicas comunitarias, siendo, así, un proceso que se retroalimentó.

Un ejemplo de esto es el caso del conjunto habitacional Santa Aurora en Constitución. A diferencia de las otras tres localidades estudiadas, el Estado reconstruyó las viviendas en el mismo lugar de origen, donde, además, la comunidad de residentes participó activamente en el proceso de reconstrucción. Los resultados nos muestran que estas personas experimentan altos grados de apego, identidad de lugar, satisfacción residencial, sentido de comunidad y participación cívica en las condiciones habitacionales actuales. Por el contrario, en el caso de Chaitén, el desplazamiento a un nuevo barrio ubicado en una ciudad distante, con un desmembramiento de la comunidad de origen, ha provocado una desvinculación y un sentimiento de desarraigo que dificulta la valoración e inserción en nuevas redes comunitarias. En este caso, la entrega de 
un bono individual a cada familia propició una búsqueda individual de viviendas, que consolidó aún más la disolución de los vínculos socioespaciales.

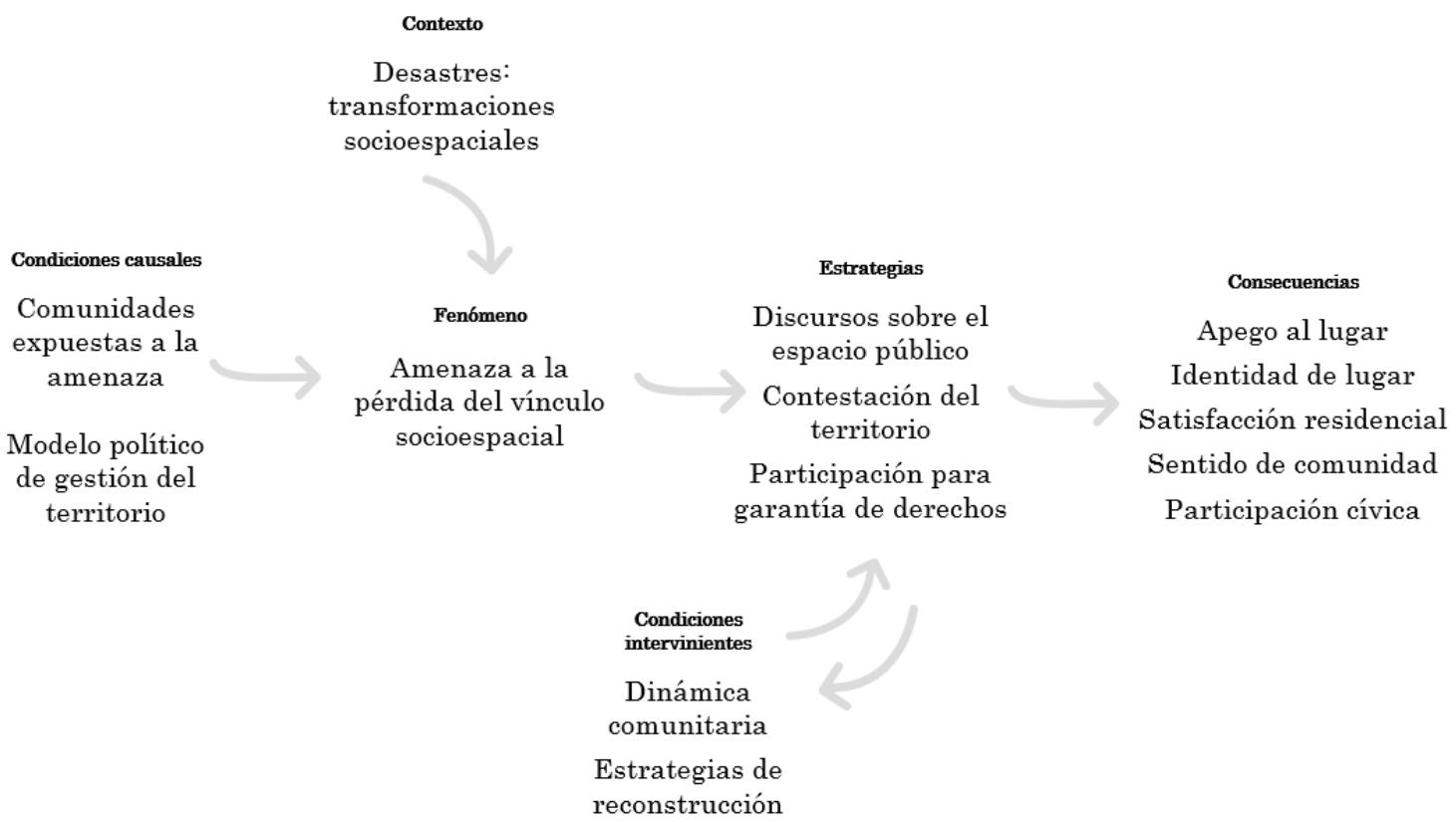

Figura 4. Integración de resultados

\section{Conclusiones}

En este texto hemos planteado explorar la afectación de las comunidades ante desastres socionaturales articulando dos subdisciplinas de la psicología (la psicología ambiental y la psicología comunitaria), para lo cual propusimos el estudio de lo que denominamos vínculos socioespaciales. En consecuencia, organizamos las conclusiones a partir de la articulación de estos campos y su potencialidad para la investigación y la intervención ante desastres socionaturales.

Considerando a Wiesenfeld (2003) y Wiesenfeld y Zara (2012), gran parte de los programas y acciones dirigidas a la población han estado orientadas por criterios técnicos, sin nutrirse de los conocimientos locales, reproduciendo relaciones de opresión y desigualdad. El vínculo ambiental-comunitario es una oportunidad de proveer un abordaje más integral a los problemas ambientales (Wiesenfeld, 2001), pretendiendo privilegiar el quehacer investigativo que protagonice la participación de sus habitantes.

Hemos identificado que, además de la articulación teórica en la comprensión de conceptos de ambas disciplinas, esta lectura amplía el entendimiento de elementos de poder y disputa del territorio, así como visibiliza falencias psicosociales en las soluciones de reconstrucción vividas por estos habitantes.

Tal como identificamos en el trabajo anterior (Berroeta \& Rodriguez, 2010), los procesos de vinculación con el lugar, las dinámicas intersubjetivas comunitarias y las transformaciones materiales en los espacios no son conceptos separables al momento de intervenir. Esto nos lleva a considerar la importancia de la transdisciplinariedad y el compromiso social en los estudios del área. Rescatando nuestra posición epistemológica, esta comprensión nos sitúa en un enfoque transaccional (Altman \& Rogoff, 1987), a partir del cual entendemos la persona, la comunidad y el ambiente como una confluencia de factores inseparables que se construyen y transforman mutuamente de modo activo (Berroeta, 2007). A nuestro juicio, el foco debe estar puesto en entender las construcciones sociales que las personas desarrollan hacia el territorio, para lo cual es necesario comprender las condiciones políticas e ideológicas que sustentan su quehacer. 
Por lo anterior, es necesario comprender cómo las personas viven, interpretan y reaccionan frente a un desastre, qué ocurre en el proceso de desplazamiento y en la eventual relocalización y cómo se reconstruyen sus vínculos con el nuevo espacio y la comunidad.

No se puede obviar que las personas tienen significados socioespaciales previos al desastre y que, ante un desplazamiento, necesariamente elaboran un duelo por lo que se pierde, lo cual evidentemente no es reductible a las pérdidas materiales. Esto es fundamental, dado que el proceso de adaptación va a depender no solo de las diferencias entre el nuevo y el viejo entorno, sino también de la posibilidad de generar vínculos sociales y espaciales satisfactorios.

En este sentido, consideramos necesario desarrollar investigaciones que den cuenta de cómo la dificultad de generar vínculos en las nuevas comunidades o barrios afecta las prácticas colectivas y los significados socioespaciales compartidos.

En términos de intervención postdesastre, consideramos que, si las acciones que se desarrollan se siguen centrando en aspectos materiales, es de esperar que los niveles de apego con los nuevos destinos sean bajos. Es indispensable que se consideren los procesos comunitarios, puesto que, como hemos observado en esta investigación, la sola satisfacción residencial con la vivienda no asegura niveles altos de sentido de comunidad, de apego de lugar, de identidad de lugar ni de participación. Esto implicaría que las acciones desarrolladas desde los gobiernos se ejecuten considerando un enfoque psicoambiental comunitario, partiendo, entonces, desde el reconocimiento de los significados y las prácticas tanto individuales como comunitarias de las poblaciones e identificando sus problemas y necesidades. Abogamos, por lo tanto, por el esfuerzo de entregar la mejor materialidad, tanto en las viviendas como en los espacios públicos, e integrar a la comunidad de manera activa a los procesos y decisiones que se desarrollan en el desplazamiento y la reconstrucción, respetando los derechos que toda comunidad tiene ante la intervención de programas sociales (Olivares-Espinoza, et al., 2018).

\section{Referencias}

Altman, I. \& Low, S. M. (1992). Place attachment. New York, NY: Plenum Press. https://doi.org/10.1007/978-1-4684-8753-4

Altman, I. \& Rogoff, B. (1987). World views in psychology: Trait, interactional, organismic and transactional perspectives. En D. Stokols \& I. Altman (Eds.), Handbook of environmental psychology (Vol. 1, pp. 7-40). New York, NY: John Wiley \& Sons.

Amérigo, M. (1995). Satisfacción residencial: un análisis psicológico de la vivienda y su entorno. Madrid, España: Alianza.

Aragonés, J. I., Amérigo, M. \& Pérez-López, R. (2017). Residential satisfaction and quality of life. En G. Fleury-Bahi, E. Pol \& O. Navarro (Eds.), Handbook of environmental psychology and quality of life research (pp. 311-328). Basel, Suiza: Springer.

Bernardo, F. \& Palma-Oliveira, J. M. (2016). Urban neighbourhoods and intergroup relations: The importance of place identity. Journal of Environmental Psychology, 45, 239-251. https://doi.org/10.1016/j.jenvp.2016.01.010

Berroeta, H., Pinto de Carvalho, L. \& Di Masso, A. (2017). Apego al lugar: una aproximación psicoambiental a la vinculación afectiva con el entorno en procesos de reconstrucción del hábitat residencial. Revista INVI, 32(91), 113-139. https://doi.org/10.4067/S0718-83582017000300113

Berroeta, H., Carvalho, L. \& Di Masso, A. (2016). Significados del espacio público en contextos de transformación por desastres socionaturales. Revista INVI, 31(87), 143-170. https://doi.org/10.4067/S0718-83582016000200005

Berroeta, H., Ramoneda, A. \& Opazo, L. (2015). Sentido de comunidad, participación y apego al lugar en comunidades desplazadas y no desplazadas post desastres: Chaitén y Constitución. Universitas Psychologica, 14(4), 15-27. https://doi.org/10.11144/Javeriana.up14-4.scpa

Berroeta, H. \& Rodriguez, M. (2012). La intervención socio-urbana del barrio las Canteras: una experiencia desde la Psicología Ambiental Comunitaria. Revista de Ciencias Sociales, 25, 78-95. Extraído de https://revistas.upr.edu/index.php/rcs/article/view/5743

Berroeta, H. \& Rodríguez, M. (2010). La transformación participativa del espacio público comunitario: análisis socioespacial de una investigación-acción. Revista electrónica de Psicología Política, 5(1), 22-34. https://doi.org/10.17163/alt.v5n1.2010.02

Berroeta, H. \& Vidal, T. (2012). La noción de espacio público y la configuración de la ciudad: fundamentos para los relatos de pérdida, civilidad y disputa. Polis, 11(31), 57-80. https://doi.org/10.4067/S0718-65682012000100004

Berroeta, H. (2007). Espacio Público: notas para la articulación de una Psicología Ambiental Comunitaria. En J. Alfaro \& H. Berroeta (eds.), Trayectoria de la Psicología Comunitaria en Chile. Prácticas y conceptos (pp.259-286). Valparaíso: Universidad de Valparaíso Editorial.

Boğaç, C. (2009). Place attachment in a foreign settlement. Journal of Environmental Psychology, 29, 267-278. https://doi.org/10.1016/j.jenvp.2009.01.001

Bonanno, G. A., Galea, S., Bucciarelli, A. \& Vlahov, D. (2006). Psychological resilience after disaster: New York city in the aftermath of the September 11th terrorist attack. Psychological Science, 17, 181-186. https://doi.org/10.1111/j.1467-9280.2006.01682.x

Borja, J. \& Muxí, Z. (2001). El espacio público: ciudad y ciudadanía. (1ª ed.). Barcelona, España: Editorial Electa.

Brown, B. \& Perkins, D. D. (1992). Disruptions in place attachment. En I. Altman \& S. Low (Eds.), Place attachment (pp. 279-304). New York, NY: Plenum Press. https://doi.org/10.1007/978-1-4684-8753-4_13

Casakin, H., Hernández, B. \& Ruiz, C. (2015). Place attachment and place identity in Israeli cities: The influence of city size. Cities, 42(B), 224-230. https://doi.org/10.1016/j.cities.2014.07.007

Chile, Gobierno Regional Bío Bío (2010). Plan de reconstrucción del borde costero - PRBC18: plan maestro Dichato. Concepción, Chile: Autor. Extraído de http://rebuilding-cities.com/Rebuilding_Cities/Course_Materials_files/Dichato\%20Master\%20Plan\%20-\%20Spanish.pdf

Chile, Ministerio del Interior y Seguridad Pública (2014). Delegación presidencia para la reconstrucción: Plan de reconstrucción de Chaitén. Santiago, Chile: Autor. Extraído de http://www.interior.gob.cl/media/2015/02/reconstruccion_chaiten.pdf 
Cornejo, M., Mendoza, F. \& Rojas, R. C. (2008). La investigación con relatos de vida: pistas y opciones del diseño metodológico. Psykhe, 17(1), 29-39. https://doi.org/10.4067/S0718-222820080001000189

Cuba, L. \& Hummon, D. M. (1993). A place to call home: Identification with dwelling, community, and region. The Sociological Quarterly, 34, 111-131. https://doi.org/10.1111/j.1533-8525.1993.tb00133.x

Di Masso, A., Berroeta, H. \& Vidal, T. (2017). El espacio público en conflicto: Coordenadas conceptuales y tensiones ideológicas. Athenea Digital, 17(3), 53-92. https://doi.org/10.5565/rev/athenea.1725

Di Masso, A. \& Dixon, J. (2015). More than words: place attachment and struggle over public space in Barcelona. Qualitative Research in Psychology, 12(1), 45-60. https://doi.org/10.1080/14780887.2014.958387

Di Masso, A., Dixon, J. \& Durrheim, K. (2014). Place attachment as discursive practice. En L. C. Manzo \& P. Devine-Wright (Eds.), Place attachment: Advances in theory, methods and applications (pp. 75-86). New York, NY: Routledge.

Di Masso, A., Dixon, J. \& Hernández, B. (2016). Place attachment, sense of belonging and the micro-politics of place satisfaction. En G. Fleury-Bahi, E. Pol \& O. Navarro (Eds.), Handbook of environmental psychology and quality of life research (pp. 85-106). Basel, Suiza: Springer.

Francis, J., Giles-Corti, B., Wood, L. \& Knuiman, M. (2012). Creating sense of community: The role of public space. Journal of Environmental Psychology, 32, 401-409. https://doi.org/10.1016/j.jenvp.2012.07.002

Fried, M. A. (1963). Grieving for a lost home: Psychological costs of relocation. En L. J. Duhl (Ed.), Urban renewal: The record and the controversy (pp. 359-379). New York, NY: Basic Books.

García Martínez, F. E., Reyes Reyes, A. \& Cova Solar, F. (2014). Severidad del trauma, optimismo, crecimiento postraumático y bienestar en sobrevivientes de un desastre natural. Universitas Psychologica, 13, 575-584. https://doi.org/10.11144/Javeriana.UPSY13-2.stop

Greenfield, E. A. \& Marks, N. F. (2010). Sense of community as a protective factor against long-term psychological effects of childhood violence. Social Service Review, 84, 129-147. https://doi.org/10.1086/652786

Guba, E. G. \& Lincoln, Y. S. (1994). Competing paradigms in qualitative research. En N. Denzin \& Y. Lincoln (Eds.), Handbook of qualitative research (pp. 105-117). Thousand Oaks, CA: SAGE.

Heller, T. (1982). The effects of involuntary residential relocation: A review. American Journal of Community Psychology, 10, 471-492. https://doi.org/10.1007/BF00893984

Hidalgo, M. C. \& Hernández, B. (2001). Place attachment: Conceptual and empirical questions. Journal of Environmental Psychology, 21, 273-281. https://doi.org/10.1006/jevp.2001.0221

Lewicka, M. (2011). Place attachment: How far have we come in the last 40 years? Journal of Environmental Psychology, 31, 207-230. https://doi.org/10.1016/j.jenvp.2010.10.001

Long, D. A. \& Perkins, D. D. (2003). Confirmatory factor analysis of the Sense of Community Index and development of a brief SCI. Journal of Community Psychology, 31, 279-296. https:// doi.org/10.1002/jcop.10046

Long, D. A. \& Perkins, D. D. (2007). Community social and place predictors of sense of community: A multilevel and longitudinal analysis. Journal of Community Psychology, 35, 563-581. https://doi.org/10.1002/jcop.20165

Mannarini, T., Tartaglia, S., Fedi, A. \& Greganti, K. (2006). Image of neighborhood, self-image and sense of community. Journal of Environmental Psychology, 26, 202-214. https://doi.org/10.1016/j.jenvp.2006.07.008

Manzo, L. C. (2003). Beyond house and haven: Toward a revisioning of emotional relationships with places. Journal of Environmental Psychology, 23(1), 47-61. https://doi.org/10.1016/S0272-4944(02)00074-9

Manzo, L. C. (2014). Exploring the shadow side: Place attachment in the context of stigma, displacement, and social housing. En L. C. Manzo \& P. Devine-Wright (Eds.), Place attachment: Advances in theory, methods and applications (pp. 178-190). New York, NY: Routledge.

Manzo, L. C. \& Perkins, D. D. (2006). Finding common ground: The importance of place attachment to community participation and planning. Journal of Planning Literature, 20, 335-350. https://doi.org/10.1177/0885412205286160

Maskrey, A. (Comp.) (1993). Los desastres no son naturales. Ciudad de Panamá, Panamá: La Red (Red de Estudios Sociales en Prevención de Desastres en América Latina).

McMillan, D. W. \& Chavis, D. M. (1986). Sense of community: A definition and theory. Journal of Community Psychology, 14, 6-23. https://doi.org/10.1002/1520-6629(198601)14:1<6::AID-JCOP2290140103>3.0.CO;2-I

Montero, M. (2004). Introducción a la psicología comunitaria: Desarrollo, conceptos y procesos. Buenos Aires, Argentina: Paidós.

Morrow, S. L. \& Smith, M. L. (1995). Constructions of survival and coping by women who have survived childhood sexual abuse. Journal of Counseling Psychology, 42, 24-33. https://doi.org/10.1037/0022-0167.42.1.24

Norris, F. H., Friedman, M. J. \& Watson, P. J. (2002). 60.000 disaster victims speak: Part II. Summary and implications of the disaster mental health research. Psychiatry: Interpersonal and Biological Processes, 65, 240-260. https://doi.org/10.1521/psyc.65.3.240.20169

Norris, F. H., Stevens, S. P., Pfefferbaum, B., Wyche, K. F. \& Pfefferbaum, R. L. (2008). Community resilience as a metaphor, theory, set of capacities, and strategy for disaster readiness. American Journal of Community Psychology, 41, 127-150. https://doi.org/10.1007/s10464-007-9156-6

Nowel, B. \& Boyd, N. (2010). Viewing community as responsibility as well as resource: Deconstructing the theoretical roots of psychological sense of community. Journal of Community Psychology, 38, 828-841. https://doi.org/10.1002/jcop.20398

Olivares-Espinoza, B., Winkler, M., Reyes-Espejo, M., Berroeta, H. \& Montero, M. (2018). ¿Y si pensamos la comunidad con derechos? Psicología Comunitaria, derechos y políticas públicas. Una relación compleja. Universitas Psychologica, 17(2), 1-13. https://doi.org/10.11144/Javeriana.upsy17-2.pcdp

Organización de las Naciones Unidas para la Educación, la Ciencia y la Cultura (2012). Análisis de riesgos de desastres en Chile: VII Plan de acción Dipecho en Sudamérica 2011-2012. Santiago, Chile: Autor.

Páez, D., Basabe, N., Bosco, S., Campos, M. \& Ubillos, S. (2011). Afrontamiento y violencia colectiva. En D. Páez, C. Martín Beristain, J. L. González, N. Basabe \& J. de Rivera (Eds.), Superando la violencia colectiva y construyendo cultura de paz (pp. 279-309). Madrid, España: Fundamentos.

Perkins, D. D., Florin, P., Rich, R. C., Wandersman, A. \& Chavis, D. M. (1990). Participation and the social and physical environment of residential blocks: Crime and community context. American Journal of Community Psychology, 18, 83-115. https://doi.org/10.1007/BF00922690

Pinto de Carvalho, L. \& Cornejo, M. (2018). Por una aproximación crítica al apego al lugar: una revisión en contextos de vulneración del derecho a una vivienda adecuada. Athenea Digital, 18(3), 1-39. https://doi.org/10.5565/rev/athenea.2004

Proshansky, H. M., Fabian, A. K. \& Kaminoff, R. (1983). Place-identity: Physical world socialization of the self. Journal of Environmental Psychology, 3, 57-83. https://doi.org/10.1016/S0272-4944(83)80021-8 
Salcedo Hansen, R. (2002). El espacio público en el debate actual: una reflexión crítica sobre el urbanismo post-moderno. EURE: Revista Latinoamericana de Estudios Urbano Regionales, 28(84), 5-19. https://doi.org/10.4067/S0250-71612002008400001

Salgado, M. (2014). Reconstrucción de la vida cotidiana. La cara invisibilizada tras el terremoto y tsunami del 2010. TS Cuadernos de Trabajo Social, 11, 34-42. Extraído de http://ojs.uss.cl/index.php/TS/article/view/11

Sanders, S., Bowie, S. L. \& Bowie, Y. D. (2004). Lessons learned on forced relocation of older adults: The impact of hurricane Andrew on health, mental health, and social support of public housing residents. Journal of Gerontological Social Work, 40(4), 23-35. https://doi.org/10.1300/J083v40n04_03

Sararit, T. (2018). Self-extensional space in relocated housing after 2004 Indian ocean tsunami: Case study of Namkem community, PhangNga, Thailand. Journal of Disaster Research, 13, 168-176. https://doi.org/10.20965/jdr.2018.p0168

Scannell, L., Cox, R. S. \& Fletcher, S. (2017). Place-based loss and resilience among disaster-affected youth. Journal of Community Psychology, 45, 859-876. https://doi.org/10.1002/jcop.21897

Scannell, L., Cox, R. S., Fletcher, S. \& Heykoop, C. (2016). "That was the last time I saw my house": The importance of place attachment among children and youth in disaster contexts. American Journal of Community Psychology, 58, 158-173. https://doi.org/10.1002/ajcp.12069

Scannell, L. \& Gifford, R. (2010). Defining place attachment: A tripartite organizing framework. Journal of Environmental Psychology, 30, 1-10. https://doi.org/10.1016/j.jenvp.2009.09.006

Silver, A. \& Grek-Martin, J. (2015). "Now we understand what community really means": Reconceptualizing the role of sense of place in the disaster recovery process. Journal of Environmental Psychology, 42, 32-41. https://doi.org/10.1016/j.jenvp.2015.01.004

Stokols, D. \& Shumaker, S. A. (1981). People in places: A transactional view of settings. En J. H. Harvey (Ed.), Cognition, social behavior, and the environment (pp. 441-488). Hillsdale, NJ: Lawrence Elrbaum.

Strauss, A. \& Corbin, J. (1990). Basics of qualitative research: Grounded theory procedures and techniques. Newbury Park, CA: Sage.

Tapia, R. (2015). Acción del Estado y acción comunitaria en la gestión de la vivienda post erupción del volcán Chaitén, Chile: dos estrategias divergentes. Magallania, 43(3), 141-157. https://doi.org/10.4067/S0718-22442015000300011

Trabka, A. (2019). From functional bonds to place identity: Place attachment of Polish migrants living in London and Oslo. Journal of Environmental Psychology, 62, 67-73. https://doi.org/10.1016/j.jenvp.2019.02.010

Valera, S. (1996). Análisis de los aspectos simbólicos del espacio urbano. Perspectivas desde la psicología ambiental. Revista de Psicología Universitas Tarraconensis, 18(1), 63-86. Extraído de http://bibliotecadigital.academia.cl/handle/123456789/593

Vick, J. W. \& Perkins, D. D. (2013). Building community: Residential satisfaction in conventional and neotraditional suburban neighborhoods. En K. Besel \& V. Andreescu (Ed.), Back to the future: New urbanism and the Return of Traditionalism within Urban and Suburban Environments (pp.89-104). Lanham, MD: University Press of America.

Vidal, T., Berroeta, H., Di Masso, A., Valera, S. \& Peró, M. (2013). Apego al lugar, identidad de lugar, sentido de comunidad y participación en un contexto de renovación urbana. Estudios de Psicología, 34(3), 275-286. https://doi.org/10.1174/021093913808295172

Vidal Moranta, T. \& Pol Urrútia, E. (2005). La apropiación del espacio: una propuesta teórica para comprender la vinculación entre las personas y los lugares. Anuario de Psicología, 36, 281-297. Extraído de https://www.raco.cat/index.php/AnuarioPsicologia/article/view/61819

Vidal, T., Valera, S. \& Peró, M. (2010). Place attachment, place identity and residential mobility in undergraduate students. Psyecology, 1, 353-369. https://doi.org/10.1174/217119710792774799

Wiesenfeld, E. (2001). La problemática ambiental desde la perspectiva psicosocial comunitaria: hacia una psicología ambiental del cambio. Medio Ambiente y Comportamiento Humano, 2(1), 1-19. Extraído de https://dialnet.unirioja.es/servlet/articulo?codigo=2110643

Wiesenfeld, E. (2003). La psicología ambiental y el desarrollo sostenible. ¿Cuál psicología ambiental? ¿Cuál desarrollo sostenible? Estudos de Psicologia, 8, 235-261. https://doi.org/10.1590/S1413-294X2003000200007

Wiesenfeld, E. \& Zara, H. (2012). La psicología ambiental latinoamericana en la primera década del milenio. Un análisis crítico. Athenea Digital, 12(1), 129-155. https://doi.org/10.5565/rev/athenead/v12n1.985

Wisner, B., Blaikie, P., Cannon, T. \& Davis, I. (2003). At risk: Natural hazards, people's vulnerability and disasters. (2a. ed.). New York, NY: Routledge.

Fecha de recepción: Abril de 2019.

Fecha de aceptación: Julio de 2019. 